This is a post-refereeing final draft. When citing, please refer to the published version:

Eichhorn V., Miller, G., Michopoulou, E., \& Buhalis, D. (2008). Enabling Access to Tourism through Information Schemes. Annals of Tourism Research, 35 (1), pp. 189-210.

doi: 10.1016/j.annals.2007.07.005

\title{
ENABLING ACCESS TO TOURISM THROUGH INFORMATION SCHEMES?
}

\author{
Victoria Eichhorn \\ Graham Miller \\ Eleni Michopoulou \\ University of Surrey, UK \\ Dimitrios Buhalis \\ Bournemouth University, UK
}

\begin{abstract}
Embedded in information search theory, this paper investigates accessibility tourism information schemes as communication sources and their potential to fulfill the informational needs of tourists with disabilities. Five interrelated need components are identified: richness and reliability of information, appropriate information sources, communication tools and customer-oriented services. The results show that, despite complying with the reliability function at the regional and national level, the existing schemes studied only partly comply with informational requirements. Limitations originate from high fragmentation and lack of geographical reach. To achieve information satisfaction and fully enable access to tourism for people with disabilities, a more sophisticated understanding of differential needs and appropriate sources is regarded as crucial.
\end{abstract}

Keywords: disability, informational needs, information search behavior, accessibility information schemes, satisfaction, performance quality 


\section{INTRODUCTION}

The heightened social responsibility encouraged through epistemological advances within the context of conceptualizing disability is an attempt to overcome many of the practical and social obstacles that people with disabilities face (Yau, McKercher and Packer 2004). The social approach to disability stresses that society needs to identify all socially constructed constraints and formulate strategies to mitigate the resulting negative tourism experiences (Daruwalla and Darcy 2005). Strategies are particularly important for the information search stage, where "the process changes from tourism as an abstract concept to resolving the practical concerns relating to ensuring a safe and enjoyable experience" (Yau et al 2004:954).

Central to accomplishing this aim is a profound understanding of the requirements of people with disabilities and the provision of adequate support services tailored towards these specific needs (Donoghue 2003; Germ and Schleien 1997; Yau et al 2004). While the provision of an accessible infrastructure is the basis for tourism participation (Pühretmair 2004), information dissemination about currently accessible destinations is equally significant (Shaw, Veitch and Coles 2005; Stumbo and Pegg 2005) and appears to be the most effective immediate solution for expanding tourism opportunities to disabled people (Cavinato and Cuckovich 2002; Darcy 1998). In fact, it can be argued, that all changes to the physical environment will not bring any benefits to the conservatively estimated 500 million people with a disability (Daruwalla and Darcy 2005; Smith 1987) if the indispensable communication of this information is missing.

Information need paradigms that affect tourism choices and tourist satisfaction levels have revealed the importance of two main conditions. First, an awareness and understanding by society and tourism providers of multiple, differential information needs (Fodness and Murray 1999; Gursoy and McCleary 2004; Vogt and Fesenmaier 1995) and second, the development of specific communication sources that fulfill individual needs (Allison 2000; Fodness and Murray 1997; Gursoy and Chen 2000; Gursoy and McCleary 2004; Vogt and Fesenmaier 1998). Whereas previous studies have begun the process of classifying different informational needs based on basic segmentation categories (Fodness and Murray 1997; Gursoy and McCleary 2004; Vogt and Fesenmaier 1998), research has yet to provide a comprehensive account of the needs of people with disabilities in terms of accessibility information.

Previously, the provision of accessibility content has been highly fragmented, inaccurate and incomprehensive (Toerisme Vlaanderen 2001). As a result, a number of approaches to 
encourage tourism accessibility (referred to in this paper as tourism accessibility schemes) have emerged in Europe over the last five years. These schemes, acting as an information communication source to assure the quality of tangible assets provided at destinations, have been set up by both, public and private sectors, with the main objective of encouraging greater equity by providing assistance to overcome the informational barriers disabled tourists face.

Although previous authors have stressed the importance of information provision and explored informational needs of disabled people (Burnett and Bender 2001; Cavinato and Cuckovich 1992; Darcy 1998; McKercher, Packer, Yau and Lam 2003; NOP Consumer 2003; Ray and Ryder 2003; Shaw et al 2005; Stumbo and Pegg 2005; Turco, Stumbo and Garnarz 1998; Yau et al 2004), research to date has not investigated if these needs have been fulfilled by the recent European proliferation of tourism access schemes. Concurrently, studies grounded in information search call for research in many areas. Principal among these is to gain insights into different types of informational needs (Fodness and Murray 1997; Gursoy and McCleary 2004; Vogt and Fesenmaier 1998). Further, all available types of information sources need to be studied (Gursoy and Chen 2000) and analyzed with the hindsight of tourists' perceptions (Fodness and Murray 1997, 1999). This paper addresses these gaps in the literature by examining European accessibility tourism information schemes and assessing them against the informational needs of persons with disabilities. Taking into consideration that behavior is a function of needs (Gibson and Yiannakis 2002) and given a potentially favorable outcome, schemes would represent an exemplary modus operandi not only to achieve information satisfaction but in so doing act as an enabling mechanism to mitigate the exclusion of disabled individuals from tourism and achieve the potential benefits tourism brings to all people.

\section{ENABLING TOURISTS WITH A DISABILITY}

Central to the nature of tourist experiences are behavioral intentions and within information search behavior theory, information seeking is regarded as an expressed need (Moutinho 1987). It is believed to be largely carried out to fulfill functional need constructs that encompass the reduction of uncertainty and risks to maximize satisfaction (Gursoy and McCleary 2004; Vogt and Fesenmaier 1998). Overall satisfaction, fundamental to tourist behavior (Kozak 2001), encompasses two major antecedents: attribute and information satisfaction, with the latter referring to "a subjective satisfaction judgment of the information 
used in choosing a product" (Spreng, MacKenzie and Olshavsky 1996:18). The assessment of information satisfaction requires first to distinguish between three distinctive features of search. First, search takes place either internally, retrieving information from memory, or externally by using different sources from the external environment (Fodness and Murray 1997, 1999; Gursoy and McCleary 2004; Moutinho 1987). Second, search processes are ongoing or specific to a problem within the pre-purchase phase (Fodness and Murray 1999; Gursoy and Chen 2000). Third, a variety of sources, embracing brochures, the internet and personal recommendations among others, reflect the conduct of search and determine tourists' value perceptions (Fodness and Murray 1999). These processes differ according to different tourist, product, and situational characteristics. Given a complex problem-solving situation, search is usually typified by external, pre-purchase behavior employing a variety of sources (Beatty and Smith 1987; Fodness and Murray 1997, 1999).

For people with disabilities, the provision of information about the state of accessible features at the destination represents a key functional need (Disability Now 2005; Imrie and Kumar 1998; McKercher et al 2003; Shaw et al 2005; Stumbo and Pegg 2005; Turco et al 1998; Yau et al 2004). The fulfillment of these needs becomes particularly crucial within the pre-travel phase as it determines whether tourism remains an abstract concept or individuals become actively engaged in tourism (Pühretmair 2004; Stumbo and Pegg 2005; Yau et al 2005). Without sufficient information regarding accessible destinations, people with disabilities are unsure if their physical needs can be met and may therefore refrain from traveling, and so fail to satisfy important social and psychological needs that include the desire for rest, relaxation, the feeling of freedom, opportunities for social interaction and the experience of visiting new places (Shaw and Coles 2004). In this respect, the fulfillment of needs does not only lead to higher information satisfaction levels but acts also as an enabler to travel.

Yau et al (2004) argue that society has to become more aware of the needs of disabled people. However, the authors of this article argue that it is not the amount of research that is lacking, but the absence of a theoretical framework for an improved understanding of the subject. This paper addresses this weakness and draws together existing findings to establish a more holistic view of informational needs (Figure 1), comprising five interrelated components: richness and reliability of information, appropriate tourism information sources, communication and customer-oriented services. 


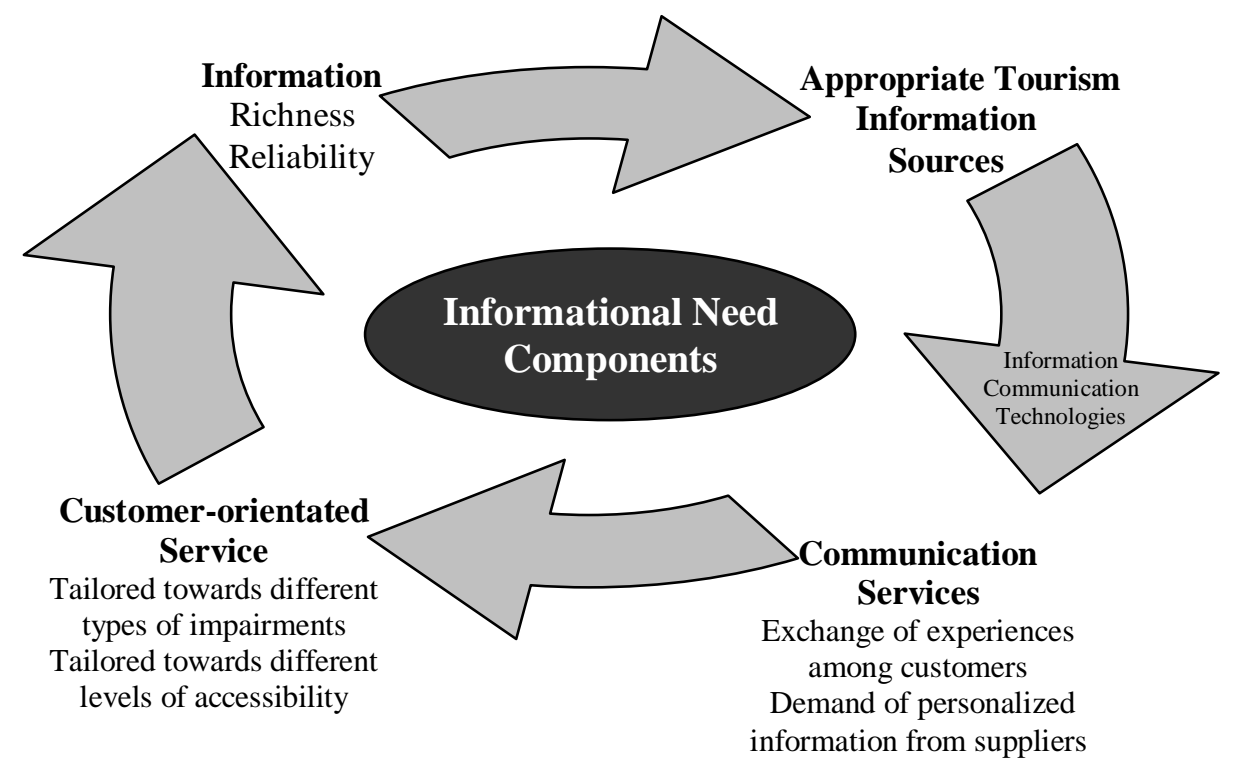

Figure 1. Framework of Interrelated Need Components

Destinations offer an amalgam of products and services, designed to meet the needs of tourists (Leiper 1995), so the dissemination of rich tourism content covering in depth and breadth all components of the entire accessible subsystem is a key prerequisite (Yau et al 2004). Particularly important is informing potential customers about continuous accessible pathways as isolated accessible facilities do not add to the tourism experience (Darcy 1998). Israeli (2002) demonstrated that subsequent to using tourism facilities, disabled people ranked the importance of accessible pathways more highly.

Cavinato and Cuckovich (2002) found, that not only the availability of rich information but also its reliability represents an essential need. The lack of reliability is one of the major causes that prevent disabled people from traveling (Darcy 1998; Darcy and Daruwalla 1999; Stumbo and Pegg 2005). In a study by NOP Consumer (2003), participants stated that credibility needs to be established through a three stage process to fulfill their travel needs. First, standards have to be set by respected disability organizations. Second, the assessment of facilities against these criteria ought to be conducted by an independent authoritative body 
and third, the subsequent information dissemination has to include clear descriptions on the criteria that lead to accreditation (NOP Consumer 2003).

The third element enabling the meeting of the needs of disabled tourists is the ability to choose appropriate tourism information sources. Many citizens with access requirements follow a multi-source planning approach because the quality of information given in single sources is usually insufficient, only partially accurate or inaccessible (Daniels, Drogin and Wiggins 2005; Darcy 1998; McKercher et al 2003) and any medium is approached with a great deal of apprehension (Cavinato and Cuckovich 1992; Darcy and Daruwalla 1999; McGuire, Dottavio and O'Leary 1986; Ray and Ryder 2003; Turco et al 1998). This multisource process also adds to the time taken to search and acts as a disincentive to travel. Darcy (1998) argues that the amount and accuracy of information provided in one single source is the most crucial requirement to better meet the planning needs of disabled people.

Cavinato and Cuckovich (2002) stress the importance of specialized public bodies as appropriate mediums for reliable information dissemination, while Cheng (2002), Burnett and Bender (2001) and Darcy (1998) emphasize that access information has to be included into mainstream channels to avoid stigmas of segregation associated with specific disabilityoriented agents. One of the shortcomings of using mainstream channels, such as travel agencies, is the deficient understanding of the particular needs of disabled people (McKercher et al 2003). Through the emergence of the internet, disabled customers have gained a powerful and independent source with which to plan their holidays (Buhalis 2003; Cavinato and Cuckovich 1992; Ray and Ryder 2003). The internet allows to search for detailed, reliable and up-to-date information since printed material is often not sufficiently accurate. Further, the internet provides dynamic opportunities to reduce and simplify the search procedure (Darcy and Daruwalla 1999; NOP Consumer 2003; Toerisme Vlaanderen 2001) and can also provide opportunities for the exchange of experiences amongst consumers. As with all tourists, people with disabilities benefit from testimonials as valuable quality criteria, and a way to establish trust through specific recommendations (NOP Consumer 2003; Ray and Ryder 2003; Turco et al 1998). Apart from sharing experiences directly with the disabled community, communication needs can also be expressed by demanding personalized information from the supplier.

Although the planning process differs from person to person, special clusters of search mechanisms exist according to different types of disability (BMWA 2004; Ray and Ryder 2003; Shaw and Coles 2004), demonstrating the need for customer-orientated services (Burnett and Bender 2001; Ray and Ryder 2003). According to personal consumer 
preferences, searches are possible according to either different types of disabilities or different levels of accessibility for each part of the destination (Disability Now 2005). Determining sets of different search needs allows a more accurate targeting of potential customers (Gibson and Yiannakis 2002).

The greatest challenge for any service-based agency is thus the provision of tourism experiences and communication sources that meet all need components of their diverse clients (Allison 2000; Fodness and Murray 1997; Gursoy and Chen 2000; Gursoy and McCleary 2004; Vogt and Fesenmaier 1998). As information satisfaction is the result of the consumer's evaluation of the organizations' communication efforts (Spreng et al 1996), sources have to be developed that focus on attributes which are important to the target market. Hence, shifting consumer needs have to be analyzed continuously as these will impact on the importance placed on attributes (Gursoy and McCleary 2004).

Several communication sources have been previously analyzed. Fodness and Murray (1997) provided a classification for commercial/non-commercial and personal/impersonal sources and Gursoy and Chen (2000) focused on 12 external sources. Accessibility tourism information schemes have not been subject to any previous investigation within this theoretical research framework. As information satisfaction primarily refers to the tangible attributes of destinations that can be controllable by service providers (Spreng et al 1996), it is this element that schemes are concentrating on (Hill and Busby 2002). Through certifying accommodation, amenities and attraction facilities and indicating accessibility standards of these assets, schemes function as information communication sources for quality assurance (Hill and Busby 2002; Toerisme Vlaanderen 2001). The accomplishment of a quality difference in the search process for disabled people is hence the major aim of schemes.

Despite their potential value, specific literature on access schemes is not available. Instead, this paper will draw on research from environmental certification schemes as research here is well-established and has strong parallels for accessibility certification. By crossing disciplinary boundaries of human ecology and disability studies, multidisciplinary perspectives within tourism are sought and found. Figure 2 is an adaption from Font (2002a), and shows that both types of schemes operate along four dimensions: setting standards, assessment, certification and accreditation of a label and acceptance and recognition in the market place. 


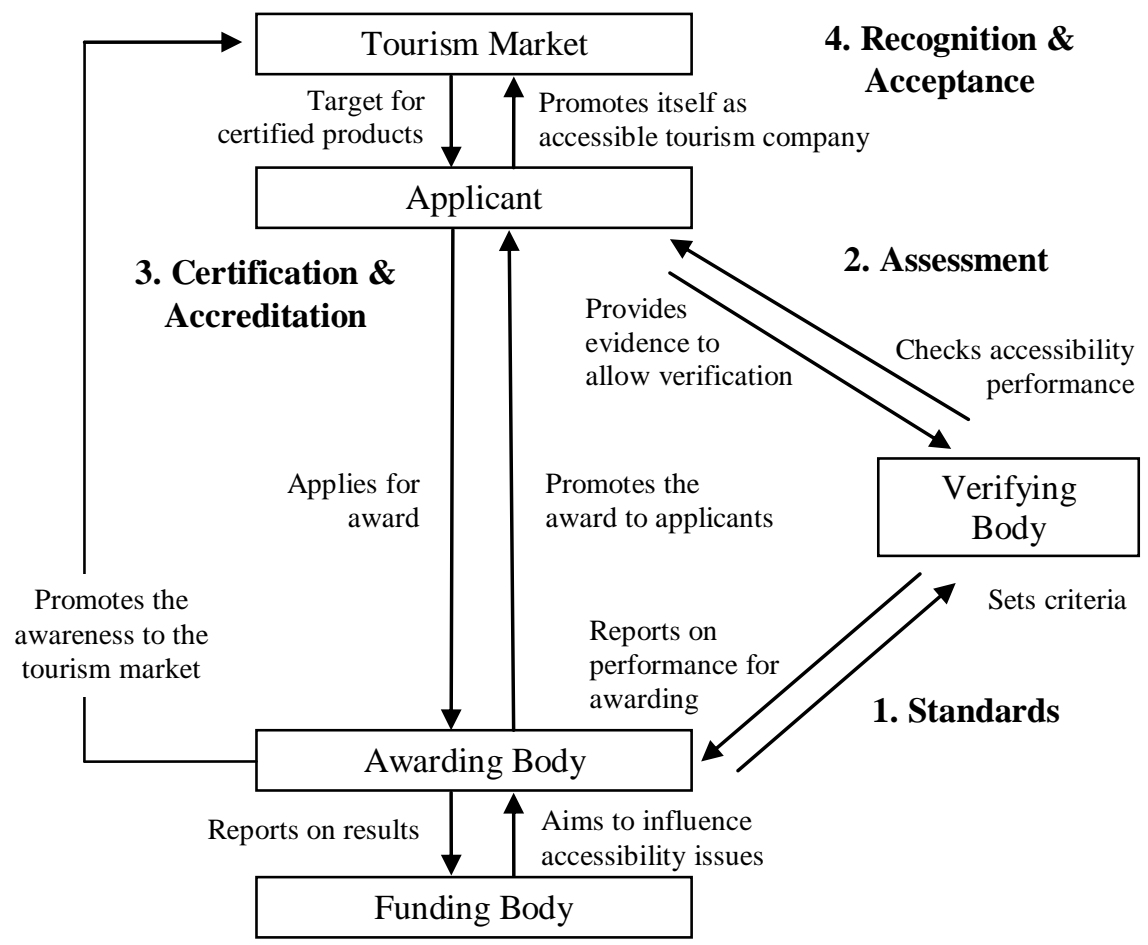

Figure 2. Accessibility Tourism Information Schemes

Environmental and accessibility certification schemes arose out of the need to bring social change through a reorganization of social arrangements and attitudes. While eco-schemes strive towards reducing environmental impacts through enhancing public environmental awareness (Buckley 2002), information access schemes are designed for combating discrimination to improve the quality of life of disabled people (Toerisme Vlaanderen 2001). The common aim of both is the acceptance by tourists that information is meaningful, reliable and useful in choosing individual products. Consumers' responses to any scheme depend on the specific social, political and economic context. Related to accessibility, a number of governments have introduced legal accessibility acts, but although vital, they are not sufficient to ensure equality for disabled people (Gleeson 1999; Imrie and Hall 2001; Miller and Kirk 2002) and national accessibility schemes have not necessarily translated to a higher participation in tourism.

Several positive and negative impacts deriving from eco-certification schemes are debated that also reflect the discussion needed within information access schemes. On the positive side, eco-certification programs strive towards higher quality standards (Medina 2005). Negatively, eco-label programs face the danger of privileging dominant interests over other needs (Sasidharan and Font 2001; Sasidharan, Sirakaya and Kerstetter 2002). Specific to access schemes, Imrie (1999) argues that at best, disabled people's views are incorporated as 
an afterthought, thus leading to the assumption that access schemes are dominated by the able-bodied population. The resulting standards set by able-bodied persons might be too low to satisfy the needs of disabled individuals.

Different perceptions as to what is an appropriate set of criteria, represents a significant area of disagreement for eco schemes (Buckley 2002; Font and Buckley 2001; Honey and Rome 2000). Particularly the proliferation of schemes causes confusion among customers, thereby impeding an effective functioning (Diamantis 1998; Honey and Steward 2002; Sanabria 2002; Sharpley 2001). There is a clear need for broadly applicable standards and harmonization of criteria at the international level, which depend on the existence of an accreditation body (Medina 2005). Its absence prevents the creation of an international label and hence fails to reach the international tourist (Font 2002a). This argument is also applicable to access schemes, which are proliferating rapidly and criteria vary between organizations and geographical settings (Toerisme Vlaanderen 2001). Further, the absence of verifying bodies generates enormous discrepancies between meeting the ideal needs of disabled customers and the reality as individuals demand assessments by independent authoritative bodies. Although the International Symbol of Access has been established, European schemes have tended to develop their own labels and symbols (Toerisme Vlaanderen 2001).

Quality labels have to communicate reliability for improving security in the planning process (Behm 1995; Bruhn and Hadwich 2004; Meffert, Burmann and Koers 2002; Pepels 2003). Crucial hereby are label-specific product attributes (Font 2002a). Access labels can either be independent, focusing exclusively on criteria for disabled people, or integrated into mainstream quality assessments. Whereas integrated labels address a wider audience and assist in overcoming stigmatizations, independent labels provide more detailed, tailor-made information for the disabled population. Thus, the choice of a particular type of label determines its appeal to peoples' needs in their planning process (Waschke 2004). Whereas doubt exists if an eco-label will influence customers' destination choice (Buckley 2002; Font 2002a), trusted access labels unquestionably affect consumers' decisions as their message determines whether or not a facility is accessible (Waschke 2004). Hence, the label function represents a boundary condition for scheme theories.

Although the World Tourism Organization shows increasing concern about service quality (Font 2002b), access schemes have not yet been examined to evaluate if they satisfy the essential information needs of disabled people. Such analysis can stimulate important debate 
within the sociocultural dimension of tourism constraints and enables society to understand the mechanisms needed for attaining societal benefits of tourism participation.

\section{Study Methods}

Multiple methods based on empirical research were employed, as the subject of need fulfillment through schemes has not received any previous investigation. Information about schemes at the European level is difficult to gather because the organizations running the schemes exist at various geographical levels. Snowball sampling was used to create an expanding chain of referrals (Browne 2005; Faugier and Sargeant 1997; Heckathorn 2002) informing the researcher about scheme operators. Snowball sampling techniques have certain limitations as they are inclined towards the selection of individuals and organizations on the basis of networks (Baxter and Eyles 1997; Biernacki and Waldorf 1981; Faugier and Sargeant 1997). This tendency was ameliorated by first establishing a detailed list of existing schemes through secondary research prior to the application of snowball sampling. As 59 organizations operating a scheme were identified through the desk research, they were sent a survey to establish their main features and also were asked to contribute to the list of known schemes. From the initial sampling, 32 surveys were received (54\%), with additional 11 from the snowball sampling.

Through this approach, a total of 43 surveys were returned, all found to be eligible for analysis, providing an inventory of schemes operating across 19 countries. However, an overall rate could not be established as many organizations forwarded the survey to other scheme operators out of their own initiative, leaving no indication as to how many were eventually forwarded. Nine of the schemes were set up by governmental or public bodies, whereas the remaining 34 were established by charities, private or non-governmental organizations. Whereas the former group offers accessibility content within a broad range of services to all citizens, the latter provides information and services exclusively for disabled people.

The survey put to the organizations was developed in consultation with a key group of individuals with disabilities and based on secondary research that established the framework of interrelated need components. The survey comprised 44 questions (open-ended and closed) divided into seven elements to analyze schemes as a communication source: descriptive data, information content, target audience, accessibility information, online and offline schemes as well as accessibility criteria. 
Building on these baseline data, captive groups (Veal 1997) were used to continue the exploratory research into the value of accessibility information schemes. Three groups were convened during two invited one-day conferences on accessibility tourism in London, United Kingdom and Athens, Greece, each lasting for 90 minutes with 15, 18 and 20 participants respectively. Experts invited to attend the conference represented a mixture of user groups, disability organizations, specialized travel agencies and tour operators as well as mainstream providers that have incorporated access information. More than half of the participants $(71 \%)$ have different types of impairments themselves, while everyone attending the meetings has more than 20 years each of experience in this area.

The captive group research comprised two main parts, a performance analysis of schemes and an evaluation of the importance given to certain scheme attributes. The performance analysis was conducted along three main themes. First, by disclosing the results of the baseline survey to the participants, features of access schemes that were valuable and helpful, or contrarily, were constraining, could be identified. This approach, often referred to as critical incident technique (Jackson, White and Schmierer 1996; Pritchard and Havitz 2006) allowed an examination into whether needs were fulfilled or remained unfulfilled, provided a balanced account of positive and negative performance levels of schemes and led to an investigation of best practice examples. Second, the future of access schemes was explored and third, participants were given the opportunity to highlight their individual perceptions on informational needs. The inductive, qualitative, exploratory nature of this research understands its limitations in making conclusions that can be generalized. Instead, what the research achieved was a deeper understanding of perceptions of need compliance through schemes and also substantiated arguments about the informational need framework deriving from secondary sources.

In order to evaluate the importance given to certain scheme attributes and strengthen claims for the validity of research, a manual analysis of the data was conducted, using Ritchie and Spencer's (1994) five interconnected stage 'framework' method of analysis. During the first stage, transcriptions of the tape-recorded discussions and notes assisted in becoming familiar with the responses, checking diversity of data and listing key ideas and recurrent themes. Notes were taken by two independent researchers during each group discussion. Each researcher conducted the 'framework' method independently. Within the familiarization stage, each researcher provided a detailed summary based on the three established categories. This summary was then presented to the participants at the end of the workshops to confirm as an accurate record and permit its accuracy. 
Within the second phase, the researchers drew upon a priori issues identified through the established need framework. Hence, the thematic framework to sift and sort material, as well as to establish connections between ideas was already developed in a previous research stage. The third stage required the coding and indexing of the transcribed focus groups. The analysis was conducted manually as the data was found to be well structured and not of an unmanageable size. Further, the use of verbatim transcripts allowed making raw material available to other researchers within the discussion section, hence further enhancing the validity of the research (Miles and Huberman 1994). Within the fourth stage, intended to chart the data for developing a pictures as a whole, the two researchers compared and discussed findings as well as identified discrepancies, adding to the reliability of the process. Using the framework of needs and access scheme features, consensus of the categorization of responses could be achieved. This allowed the interpretation of data within the fifth stage and the establishment of compliance levels which the study result section will elaborate on.

\section{Study Results}

Nearly $52 \%(\mathrm{n}=22)$ of responses from the scheme providers showed that the schemes were introduced after the year 2000, demonstrating that the supply of access information through schemes is a recent phenomenon. Analyzing the results from the accessibility scheme survey in relation to the epistemological framework of needs revealed that the majority of certification schemes were shown to comply with the reliability function at the regional or national level. However, the high fragmentation of schemes in terms of their incompleteness of information given due to different laws, access standards, assessment and evaluation techniques and lack of geographical reach causes enormous deficiencies. Among the most prevailing shortcomings are: the lack of rich information, the failure to provide customeroriented services and the inability of information distribution and communication strategies using mainstream channels. These deficiencies occur as the majority of scheme operators such as charities, private and non-governmental organizations mainly rely on funding, and hence have restricted opportunities to grow. Indeed, for many organizations the competition for funding prohibits cooperation, and so encourages fragmentation.

Reliability of Information. Most tourism access schemes are held to offer greater reliability than previously given by traditional suppliers. To ensure that a disabled person receives reliable information, the data have to be accurate, recent and constantly updated. In 29 
schemes, accessibility content is not older than one year. Yet, in only 15 out of 43 schemes, operators of a scheme update their database constantly. Abstaining from a regular update puts under risk the usefulness and trustworthiness of the information and/or gives less attention to recently modified facilities that are still unknown to the public.

Related to reliability is the method of how the information is collected. A detailed recording of measurements and other factual data of the site or facility is crucial to ensure that the needs of disabled people are met. In nearly half of the identified schemes (43\%), the information is collected by professionals who have received specific training. These professionals, usually employees of the organization operating a scheme, follow a set of accessibility criteria that is developed by the organization itself $(n=18)$. The majority of organizations in Europe act as one entity for awarding and verifying facilities. For example, the Flemish scheme that grants the award sends out its own assessors for the appraisal of facilities (Toegankelijk Vlaanderen 2004). The National Tourist Board 'Visit Britain' however, in addition to its own assessors, uses an independent charity 'Tourism for All' as an accredited inspector (Visit Britain 2005). Visits by an independent verifying body are regarded by disabled people as the most reliable form for the collection of information as opposed to the compilation of data by the awarding body itself (NOP Consumer 2003).

After compiling information, the actual assessment is based on gradual or general evaluation techniques. Gradual assessment is continuous, providing a ranking scale of different accessibility levels, whereas dichotomous, general assessment focuses on a yes/no type of evaluation. Gradual assessments are more beneficial for disabled persons as a hotel acknowledged on a general evaluation technique as inaccessible might still be accessible for visually-impaired people. It is the level of detail provided that makes a difference for dissimilar user groups. The majority of schemes employ gradual evaluation techniques $(56 \%)$ assigned to the whole facility (25\%), each part of the facility (44\%) or each type of disability (31\%). Gradual forms of assessment also bring important advantages for continuous rounds of improvements of facilities that ought to be encouraged by any scheme (Font 2002a).

In only $28 \%$ of the cases, user experience is an important component for the assessment of facilities. Vogt and Fesenmaier (1995) argue that it is particularly the evaluation of user experiences that is critical to the overall service evaluation. The involvement and consultation of disabled people is thus a crucial aspect to ensure that practices correspond to their needs (Imrie and Kumar 1998). The value of qualitative comments by disabled people is currently not utilized by organizations operating access schemes in Europe. 
Richness of Information. The deficiency of providing comprehensive tourism content is apparent throughout all schemes, whether operating at the national (56\%), regional (19\%) or local level (21\%). Only two schemes have a European-wide coverage. As depth and breadth to the information is crucial, the geographical scope and the number of facilities covered by schemes indicate an important need fulfillment component. The schemes under investigation, showed a positive relationship between these two elements. Whereas national schemes generally cover more than 2000 facilities, regional schemes less than 1000 and city based schemes less than 500, in some cases not even 50. Most access schemes inform customers about hotels, bars, restaurants, museums and theaters. Less information is provided for natural areas. Customer's choice is thus restricted to the type of facilities addressed in a specific geographical area.

To provide a fully inclusive experience to all customers, the whole tourism sub-system that is currently accessible needs to be covered. In the schemes evaluated, $90 \%$ offer access information for all parts of the tourism facility that are open to the public, but only 58\% indicate how to get to these facilities by making references to paths, public transport or other modes of transportation. This shortcoming adds to the exclusion of disabled people as isolated accessible facilities do not enable true holiday experiences. To overcome this limitation, some organizations $(n=21)$ have incorporated reference points to other tourist information services. This however, does not reduce the search process and means that although specific details about accessible facilities are given, value-added information about the whole destination is missing. According to Marston and Golledge (2003), overcoming structural barriers in terms of the most direct accessible route to their next destination is crucial for disabled individuals. Its absence leads to the creation of new barriers rather than the removal of existing ones.

Customer Orientation of Information. As people with different impairments have different requirements, customer-oriented services and tailor-made information represent a crucial part for the fulfillment of individual needs, which schemes at present fail to provide. Currently, there is a clear bias towards considering the needs of mobility-impaired people. Almost all schemes $(n=39)$ provide advice for persons using a wheelchair or mobility aids. Blind or partially-sighted persons and deaf or hard of hearing citizens are only partly covered by the schemes $(n=25 ; n=23)$. Information for people with hidden disabilities such as asthma, allergies or intellectually-impaired individuals is missing. 
Only half of the schemes provide a detailed description of the degree of accessibility of the facility through objective measurements. Concrete measurements such as the width of doors enable customers to decide for themselves if a facility is accessible for them. About half of the schemes (49\%) use pictograms besides textual content, focusing either on different parts of the facility $(n=7)$, different types of disabilities $(n=7)$ or different levels of accessibility $(n=8)$. As customers have different requirements and either search for information related to their disability or seek general accessibility details for each part of the facility (Disability Now 2005), the absence of customer-oriented services strongly conflicts with their needs.

Distribution of Information and Communication Strategies. The failure to disseminate and promote access information in mainstream channels and the inability to make full use of communication tools through information technology results in an inappropriate distribution and communication strategy for people with special needs. The majority of all schemes $(n=39)$ use the internet, either as the sole method of dissemination or in combination with printed formats $(n=22)$ or via the telephone $(n=15)$. Few schemes $(n=13)$ provide email services and only one scheme requires users to register with their personal data. Whereas $56 \%$ state that their internet services are accessible for all impairments groups, surprisingly only seven of these have a label for the accessibility of the information on websites, such as 'Bobby Approved". This failure results in an inability to satisfy particularly the needs of visually-impaired individuals that are targeted by $58 \%$ of the schemes.

The distribution is further restricted as only 17 of the analyzed schemes promote accessibility content within general tourist information or build partnerships with tourist offices. Out of 12 schemes providing a label, less than half of these are integrated labels that are also used by the tourism industry. National organizations operating schemes are at the forefront to use a variety of promotion channels, building a network of Destination Management Organizations $(47 \%)$ and public authorities $(43 \%)$ to endorse the need for access information in mainstream websites.

As the internet introduces a whole range of new tools, several benefits in terms of enhanced communication and interactivity between organizations and users and between users themselves are available. Different forms of communications enable users to state their needs based on their personal characteristics (Pan and Fesenmaier 2006). However, most of the schemes do not take advantage of these new opportunities. Less than half of the organizations operating a scheme allow users to personalize the information they are looking for by type of disability $(n=5)$, by type of facility $(n=4)$ or through a personal filter $(n=5)$, 
where content is generated based on user request. Further, only three schemes provide the possibility to exchange experiences about destinations with other users to see and add testimonials.

\section{Do Access Schemes Enable Tourists with a Disability?}

Organizations operating accessibility tourism information schemes have started a dialogue to formulate informational strategies to mitigate the exclusion of disabled people in tourism participation. Despite their valuable intentions, they are not able to achieve consumer informational satisfaction and therefore cannot provide an 'enabling' function to tourism opportunities. Consumers' perceptions of access schemes clearly authenticate and verify these findings. The high fragmentation and proliferation of existing schemes lead to an everincreasing confusion amongst customers. Further, the lacking initiative to harmonize access standards results in very limited coordination and cooperation amongst European access schemes. From a disabled person's point of view, this deficiency presents major barriers for the fulfillment of functional needs enabling a holiday with confidence and in security. It forces disabled tourists to either stay in the region where they know the standards or abandon the idea of traveling. One key mobility-impaired informant during the expert group discussions summarized this point of view:

What we really need is not another scheme. We already have seen many good examples of access schemes throughout Europe. We have to focus now on harmonizing existing schemes. For this, we need to bring together best-practice examples and create common standards and criteria at the European level.

Best-practice features of schemes include the fulfillment of the reliability function for customers through professionals visiting facilities, checking accessibility and evaluating results based on gradual methods. This process may still be improved by enhancing the involvement of disabled individuals in the assessment and evaluation process to better communicate their needs. Thus, the creation of common European standards, assessment and evaluation techniques involving disabled people's opinions, would help to collectively prioritize their needs and choose means for meeting them.

Expanding the geographical reach of access information in Europe and worldwide also means tackling problems related to the current use of a variety of different labels and symbols 
as these present a further constraint in the process. Although some scheme operators provide definitions for each label, and can be careful in the choice of the criteria and the subsequent assessment, individuals appear not to understand or remember different labels. As a result, an international labeling system would be appropriate to overcome limitations. Hence, it is important to focus on an integrated label as it is less discriminatory, increases the importance of barrier-free tourism in society and provides exemplary opportunities to combine access details for all facilities and particular paths with comprehensive destination information. This is crucial as it is the attractiveness of the destination that should be the motivator for traveling and not the level of accessibility of the facility. Dattilo (2002) pointed out that 'choice' means freedom to choose among many equivalent options, not between lesser qualities, poor quality or no options at all. Consequently, including accessibility content, certified through schemes, into mainstream information sources can be regarded as the most appropriate way to bridge the gap between the need for reliable accessibility data and content-rich destination information. As one mobility-impaired person emphasizes, mainstreaming is a central need of people with disabilities:

For me who has an impairment, tourism will not be inclusive when all the information I need is not available in the same channels that my able-bodied counterparts use.

Particularly the internet as a mainstream source provides unique opportunities to disseminate and promote this information as well as to create an improved communication structure. The director of an access scheme in the Wallonian part of Belgium and mobilityimpaired himself defines his informational needs in form of a pyramid. At the bottom part of the pyramid, he has to be ensured first that all aspects of his accessibility requirements are covered. After the second stage, where all the information has to be available easily over the internet, he describes the third level of this needs pyramid as:

My third informational need refers to being involved in the search process right from the beginning. I want to share my fear and experiences with other people who have similar doubts that I have when traveling. The contact with other people in my situation is encouraging. Especially through my assistive technology for using the internet, this became a reality now and minimizes my risks when traveling. 
However, until now, only a few scheme operators mainstream their information and ignore the possibilities to create an improved communication structure. The current failure to respond positively to the needs of disabled people, demanding interactive tools for sharing experiences and allowing them to retrieve more personalized details through personal profiles and search facilities, separates schemes from fully dismantling constraints. One of the focus group participants, who experiences blind-deafness, emphasizes the need for personalized information:

Our needs are far too often overlooked in tourism and generally in society. People just assume that by giving separate information for blind and for deaf people is sufficient enough to fulfill our requirements. However blind-deafness goes far beyond the needs of merely combining the two.

As people may have the same disability but not the same level of functioning, the need for tailor-made information is an important requirement, particularly for people with multiple disabilities. Again, the internet was held by the expert groups to represent potentially the most powerful enabler for the provision of differentiated products.

As tourism is a right for the able-bodied population as well as for people living with a disability, there is a strong need to focus on individual needs. As information search starts with the recognition of, for example, functional needs (Pan and Fesenmaier 2006), it can be asserted that only by leaving more scope for a detailed understanding of these needs, will schemes be able to represent an external communication source in the pre-travel phase that fully accomplishes information satisfaction and prevents the increasing marginalization of people living with a disability from tourism opportunities.

\section{CONCLUSION}

This paper has offered an expansion of current knowledge by incorporating information search theory more rigorously into the nature of tourism behavior constructs, particularly when investigating desired tourism experiences. Central for these constructs are evaluations of performance quality and overall satisfaction, with performance quality referring to the providers' output as antecedents of satisfaction levels and satisfaction itself representing the tourist's outcome (Baker and Crompton 2000; Pritchard and Havitz 2006). 
Having adopted a need-based definition of satisfaction, where satisfaction is seen to be related to the fulfillment of needs (Tian-Cole and Crompton 2003), this study provided an expanded synthesis and discussion by examining for the first time the scope of interrelated functional needs of people with disabilities within the information gathering process before consumers interact with the destination. The extent of interrelated need components encompasses the provision of reliable and rich information, appropriate tourism information sources, communication, and personalized customer services. For the fulfillment of these needs, accessibility tourism information schemes, as one specific type of external information communication source were examined. Given that information sources are regarded as antecedents of performance quality and that individuals do not have to be exposed to the destination to form quality performance perceptions of communication tools (Baker and Crompton 2000; Tian-Cole and Crompton 2003), the identified needs were assessed against the operation of schemes, which have not been contemplated in previous research.

Considering the complexity and variety of approaches for the measurement of perceptions, the use of qualitative methods were found to be most suitable and opportune (Pritchard and Havitz 2006) to represent disabled consumers' true perceptions of the sources available to them for trip planning. Hence, explorative research using focus groups was instrumental to addressing the dimensions underlying information source preferences. Access schemes are relevant examples of communication sources that could potentially assist in providing a quality difference in the search process to remove informational constraints. However until now, findings showed that despite complying with the reliability function at the regional and national level, major deficiencies prevent schemes from fully satisfying individual informational needs. Originating from the high fragmentation of schemes and the lack of geographical reach, shortcomings include the lack of providing comprehensive tourism information using mainstream distribution mediums, the failure to provide personalized customer-orientated services addressing different search needs as well as the negligence to offer options for enhanced communication possibilities. Resulting from these discrepancies, the nature of every scheme restricts the focus to narrow target groups and limited information provision in disperse geographical settings.

Based on these findings, the study highlights how different needs and perceptions of quality of information sources lead to different search outcomes, thereby manifesting results from previous research emphasizing commonalities between consumer behavior and information search theory for decision making processes (Vogt and Fesenmaier 1998). It is argued that a more sophisticated understanding of differential needs and appropriate sources 
is crucial not only to achieve information satisfaction but to enable people with disabilities to participate in tourism. Previous studies have neglected this significance as it was assumed that exceeding the level of information sources would bring only relatively little increase in satisfaction and optimal investment of resources is reached when minimum acceptable level of performance quality for information is achieved (Baker and Crompton 2000). Kozak (2001) argued that the actual holiday experience is the most crucial determinant for satisfaction constructs, with pre-trip considerations only setting expectations. However, given different individual needs and perceptions for different target groups, high levels of performance quality in information sources clearly represent the key for high satisfaction levels, hence determining behavioral intentions as to whether or not a person is able to travel.

The research provides two major practical implications. First, the understanding gained within this study opens up several opportunities for service providers to address different types of needs with the aim to improve customer information satisfaction by developing communication sources that explicitly target individual needs in the pre-purchase search process. Higher performance quality of communication sources and levels of satisfaction would further increase loyalty and intentions to recommend specific information sources. Specific to scheme operators, the creation of a European-wide scheme, incorporating all existing players, would move beyond the geographical and conceptual narrowness of existing schemes. Second, as asserted by Pritchard and Havitz (2006), experience constructs need to be evaluated as a whole which would generate industry guidelines for improving experiences. Specific to this study, by providing accessibility information, attribute satisfaction, referring to consumers' perception on the actual product outcome (Spreng et al 1996) can also be enhanced. Considering that the communication of accessibility features may help greatly to identify where environmental barriers have been removed or contrarily are still in existence, would hence stimulate the removal of physical barriers.

This research contains some limitations that future studies should engage with. Positioned in the behavioral stream of literature, the research focused on functional information need constructs in the pre-purchase, external search process and their fulfillment through schemes. The analysis of schemes was geographically restricted to a European context. Hence, future studies need to address differences between schemes outside Europe and identify if the findings reported within Europe are repeated elsewhere, thereby assisting to achieve empirical generalization. Additional research is also needed to inform about other need constructs such as hedonic, innovation, aesthetic and sign information roles (Vogt and 
Fesenmaier 1998) as well as the influence of prior knowledge (Gursoy and McCleary 2004) for this target group.

Numerous studies deal with appraisal satisfaction (Alabacete-Sáez, Fuentes-Fuentes and Lloréns-Montes 2007; Baker and Crompton 2000; Khan 2003; Kozak 2001), referring to tourists' actual comparison of service outcome and expectations during the holiday trip. However, the authors of this article argue that it is essential to include aspects on informational satisfaction prior to the interaction with the destination into existing frameworks assessing performance quality, satisfaction and behavioral intentions. As overall satisfaction is derived through both, information and attribute satisfaction (Baker and Crompton 2000; Tian-Cole and Crompton 2003), future studies need to embrace both elements to identify the full array of satisfaction constructs for individual tourists in situations in which consumers' needs for information varies (Spreng et al 1996). Essential in this context are tourists' perceptions of quality as these remain at the core of satisfaction (Alegre and Juaneda 2006) and need aspects as their fulfillment also leads to satisfaction judgments (Baker and Crompton 2000), particularly within the travel preparation stage. Hence, continuing research revealing different need constructs contribute to satisfaction evaluations, which in turn provides valuable feedback to service providers which can subsequently be addressed.

By moving towards new dialogues and strategies, inclusive opportunities can be enhanced and ultimately enable all people who would be tourists. Tourism participation and the enjoyment of its broader societal benefits highly depend on the performance quality of providers in terms of information communication sources as well as destination attributes. Until society understands the full extent of different interrelated need components of individuals, satisfaction constructs and behavioral intentions prior as well as during the holiday, the dissonance between needs and current practices will result in ever decreasing cultural and social opportunities. In contrast, meeting differential informational requirements of all individuals adds to the power of tourism to reduce social exclusion.

Acknowledgements-This research has been funded by the OSSATE project under the European Union eContent Program (EDC-11278 OSSATE). The authors would like to acknowledge the contribution of Ivor Ambrose from EWORX and the OSSATE consortium members for contribution. The authors are particularly grateful to Steven Vos for administering the survey on accessibility information schemes. 


\section{REFERENCES}

Alabacete-Sáez, C., M. Fuentes-Fuentes, and F. Lloréns-Montes

2007 Service Quality Measurement in Rural Accommodation. Annals of Tourism Research 34:45-65.

Alegre, J., and C. Juaneda

2006 Destination Loyalty: Consumers' Economic Behavior. Annals of Tourism Research 33:684-706.

Allison, M.

2000 Leisure, Diversity and Social Justice. Journal of Leisure Research 32:2-6.

Baker, D., and J. Crompton

2000 Quality, Satisfaction and Behavioral Intentions. Annals of Tourism Research 27:785804.

Baxter, J., and J. Eyles

1997 Evaluating Qualitative Research in Social Geography: Establishing 'Rigour' in Interview Analysis. Transactions of the Institute of British Geographers 22:505-525.

Beatty, S., and S. Smith

1987 External Search Effort: An Investigation Across Several Product Categories. Journal of Consumer Research 14:83-95.

Behm, H.

1995 Erhöhte Angebotstransparenz durch Gütesiegel. In Umweltschonender Tourismus:

Eine Entwicklungsperspektive für den ländlichen Raum, P. Moll, ed., pp. 173-178. Bonn: DVGA.

Biernacki, P., and D. Waldorf

1981 Snowball Sampling: Problems and Techniques of Chain Referral Sampling. Sociological Methods and Research 10:141-163.

\section{BMWA}

2004 Economic Impulses of Accessible Tourism for All. Report, Berlin:

Bundesministerium für Wirtschaft und Arbeit.

Browne, K.

2005 Snowball Sampling: Using Social Networks to Research Non-Heterosexual Women.

International Journal of Social Research Methodology 8:47-60.

Bruhn, M., and K. Hadwich 
2004 Qualitätswahrnehmung and Qualitätszeichen bei Touristischen Dienstleistungen. In Qualitätszeichen im Tourismus. Vermarktung und Wahrnehmung von Leistungen, K.

Weiermair and B. Pikkemaat, eds., pp. 5-19. Berlin: Erich Schmidt Verlag.

Buckley, R.

2002 Tourism Eco-labels. Annals of Tourism Research 29:183-208.

Buhalis, D.

2003 eTourism: Information Technology for Strategic Tourism Management. Harlow: Prentice Hall.

Burnett, J., and H. Bender Baker

2001 Assessing the Travel-Related Behaviors of the Mobility-Disabled Consumer. Journal of Travel Research 40:4-11.

Cavinato, J., and M. Cuckovich

1992 Transportation and Tourism for the Disabled: An Assessment. Transportation Journal 31(3):46-53.

Cheng, K.

2002 What Marketers Should Know about People with Disabilities <www.nod.org/index.cfm?fuseaction=page. viewPage\&pageID=1430\&nodeID=1\&Featur eID=723\&redirected=1\&CFID=1639049\&CFTOKEN=22690084> (28 October 2005).

Daniels, M., E. Drogin, and B. Wiggins

2005 "Travel Tales": An Interpretive Analysis of Constraints and Negotiations to Pleasure

Travel as Experiences by Persons with Physical Disabilities. Tourism Management 26:919-930.

Darcy, S.

1998 Anxiety to Access: Tourism Patterns and Experiences of New South Wales People With a Physical Disability. Sydney: Tourism New South Wales.

Darcy, S., and P. Daruwalla

1999 The Trouble with Travel: People with Disabilities and Travel. Social Alternatives $18(1): 41-46$.

Daruwalla, P., and S. Darcy

2005 Personal and Societal Attitudes to Disability. Annals of Tourism Research 32:549570.

Dattilo, J.

2002 Inclusive Leisure Services: Responding to the Rights of People with Disabilities. State College, PA: Venture Publishing. 


\section{Diamantis, D.}

1998 Consumer Behavior and Ecotourism Products. Annals of Tourism Research 25:515518

Disability Now

2005 Disabled People's Needs. Athens. Unpublished Document.

Donoghue, $\mathrm{C}$.

2003 Challenging the Authority of the Medical Definition of Disability: An Analysis of the

Resistance to the Social Constructionist Paradigm. Disability and Society 18:199-208.

Fodness, D., and B. Murray

1997 Tourist Information Search. Annals of Tourism Research 24:503-523.

1999 A Model of Information Search Behavior. Journal of Travel Research 37:220-230.

Faugier, J., and M. Sargeant

1997 Sampling Hard to Reach Populations. Journal of Advanced Nursing 26:790-797.

Font, $\mathrm{X}$.

2002a Environmental Certification in Tourism and Hospitality: Progress, Process and Prospects. Tourism Management 23:197-205.

2002b Certification Systems and Standards in Tourism. Annals of Tourism Research 29:869-871.

Font, X., and R. Buckley, eds.

2001 Tourism Ecolabelling: Certification and Promotion of Sustainable Management. Wallington: Cab International.

Germ, P., and S. Schleien

1997 Inclusive Community Leisure Services: Responsibilities of Key Players. Therapeutic Recreation Journal 31:22-37.

Gibson, H., and A. Yiannakis

2002 Tourist Roles - Needs and the Lifecourse. Annals of Tourism Research 29:358-383.

Gleeson, B.

1999 Geographies of Disabilities. London: Routledge.

Gursoy, D., and J. Chen

2000 Competitive Analysis of Cross Cultural Information Search Behavior. Tourism Management 21:583-590.

Gursoy, D., and K. McCleary

2004 An Integrative Model of Tourists' Information Search Behavior. Annals of Tourism Research 31:353-373. 
Heckathorn, D.

2002 Respondent-Driven Sampling II: Deriving Valid Population Estimates from ChainReferral Samples of Hidden Populations. Social Problems 49:11-34.

Honey, M., and A. Rome

2000 Ecotourism and Sustainable Tourism Certification. Draft Report prepared for the Ecotourism and Sustainable Ecotourism Certification Workshop. 17-19 November. New Paltz, New York.

Honey, M., and E. Steward

2002 The Evolution of 'Green' Standards for Tourism. In Ecotourism and Certification, M.

Honey, ed., pp. 33-71. Washington DC: Island.

Hill, R., and G. Busby

2002 An Inspector Calls: Farm Accommodation Providers' Attitudes to Quality Assurance in the County of Devon. International Journal of Tourism Research 4:459-478.

Imrie, R.

1999 The Role of Access Groups in Facilitating Accessible Environments for Disabled People. Disability and Society 14:463-482.

Imrie, R., and P. Hall

2001 An Exploration of Disability and the Development Process. Urban Studies 38:333350.

Imrie, R., and M. Kumar

1998 Focusing on Disability and Access in the Built Environment. Disability and Society $13: 357-374$.

Israeli, A.

2002 A Preliminary Investigation of the Importance of Site Accessibility Factors for

Disabled Tourists. Journal of Travel Research 41:101-104.

Jackson, M., G. White, and C. Schmierer

1996 Tourism Experiences within an Attributional Framework. Annals of Tourism Research 23:798-810.

Khan, M.

2003 ECOSERV: Ecotourists' Quality Expectations. Annals of Tourism Research 30:109124.

Kozak, M.

2001 Repeaters' Behavior at Two Distinct Destinations. Annals of Tourism Research 28:784-807. 
Leiper, N.

1995 Tourism Management. Melbourne: RMIT Press.

Marston, J., and R. Golledge

2003 The Hidden Demand for Participation in Activities and Travel by Persons who are

Visually Impaired. Journal of Visual Impairment and Blindness 97:475-489.

McGuire, F., D. Dottavio, and J. O’Leary

1986 Constraints to Participation in Outdoor Creation Across the Life Span: A Nation-Wide

Study of Limitors and Prohibitors. The Gerontologist 26:528-544.

McKercher, B., T. Packer, M. Yau, and P. Lam

2003 Travel Agents as Facilitators or Inhibitors of Travel: Perceptions of People with

Disabilities. Tourism Management 24:465-474.

Medina, L.

2005 Ecotourism and Certification: Confronting the Principles and Pragmatics of Socially

Responsible Tourism. Journal of Sustainable Tourism 13:281-295.

Meffert, H., C. Burmann, and M. Koers

2002 Stellenwert and Gegenstand des Markenmanagements. In Markenmanagement:

Grundlagen der identitätsorientierten Markenführung, H. Meffert, C. Burmann and M.

Koers, eds., pp. 3-15. Wiesbaden: Gabler.

Miles, M., and A. Huberman

1994 Qualitative Data Analysis: An Expanded Sourcebook. London: Routledge.

Miller, G., and E. Kirk

2002 The Disability Discrimination Act: Time for a Stick? Journal of Sustainable Tourism $10: 82-88$.

Moutinho, L.

1987 Consumer Behaviour in Tourism. European Journal of Marketing 21(10):5-44.

NOP Consumer

2003 Holiday-Taking and Planning Amongst People with a Disability. London: NOP Consumer.

Pan, B., and D. Fesenmaier

2006 Online Information Search: Vacation Planning Process. Annals of Tourism Research 33:809-832.

Pepels, W.

2003 Produktmanagement: Produktinnovation, Markenpolitik, Programmplanung, Prozessorganisation $\left(4^{\text {th }}\right.$ ed.). München: Oldenbourg. 
Pritchard, M., and M. Havitz

2006 Destination Appraisal: An Analysis of Critical Incidents. Annals of Tourism Research $33: 25-46$.

Pühretmair, F.

2004 It's Time to Make eTourism Accessible. In Computers Helping People with Special Needs, K. Miesenberger, J. Klaus, W. Zagler and D. Burger, eds., pp. 272-279. Berlin: Springer Verlag.

Ray, N., and M. Ryder

2003 "Ebilities" Tourism. An Exploratory Discussion of the Travel Needs and Motivations of the Mobility Disabled. Tourism Management 24:57-72.

Ritchie, J., and L. Spencer

1994 Quality Data Analysis for Applied Policy Research. In Analyzing Qualitative Data, A.

Bryman and R. Burgess, eds., pp. 173-194. London: Routledge.

Sanabria, R.

2002 Accreditation: Certifying the Certifiers. In Ecotourism and Certification, M. Honey, ed., pp. 325-356. Washington DC: Island.

Sasidharan, V., and X. Font

2001 Pitfalls of Ecolabelling. In Tourism Ecolabelling, X. Font and R. Buckley, eds., pp. 105-119. Oxon: CAB International.

Sasidharan, V., E. Sirakaya, and D. Kerstetter

2002 Developing Countries and Ecolabels. Tourism Management 23:161-174.

Sharpley, R.

2001 The Consumer Behaviour Context of Ecolabelling. In Tourism Ecolabelling, X. Font and R. Buckley, eds., pp. 41-55. Oxon: CAB International.

Shaw, G., and T. Coles

2004 Disability, Holiday Making and the Tourism Industry in the UK: A Preliminary Survey. Tourism Management 25:397-404.

Shaw, G., C. Veitch, and T. Coles

2005 Access, Disability, and Tourism: Changing Responses in the United Kingdom. Tourism Review International 8:167-176.

Smith, R.

1987 Leisure of Disabled Tourists - Barriers to Participation. Annals of Tourism Research 14:376-389.

Spreng, R., S. MacKenzie, and R. Olshavsky 
1996 A Reexamination of the Determinants of Consumer Satisfaction. Journal of Marketing $60(3): 15-32$.

Stumbo, N., and S. Pegg

2005 Travellers and Tourists with Disabilities: A Matter of Priorities and Loyalties.

Tourism Review International 8:195-209.

Tian-Cole, S., and J. Crompton

2003 A Conceptualization of the Relationship between Service Quality and Visitor

Satisfaction, and their Links to Destination Selection. Leisure Studies 22:65-80.

Toegankelijk Vlaanderen

2004 Accessibility Analysis <www.toevla.be/default.aspx?cat=34\&taal=4> (25 October 2005).

Toerisme Vlaanderen

2001 Tourism for All in the European Union. Status Report on Tourist Accommodation

Schemes in Europe. "Tourism for all" - Meeting of EU Ministers of Tourism, 1 ' 2 July, Brugge.

Turco, D., N. Stumbo, and J. Garncarz

1998 Tourism Constraints for People with Disabilities. Parks and Recreation 33(9):78-84.

Veal, A.

1997 Research Methods for Leisure and Tourism: A Practical Guide. Harlow: Pearson.

Visit Britain

2005 Facilities for the Disabled <www.visitbritain.com/VB3-en-

US/practicalinformation/planning/facilitiesfordisabled.aspx> (25 October 2005).

Vogt, C., and D. Fesenmaier

1995 Tourist and Retailers' Perceptions of Services. Annals of Tourism Research 22:763780.

1998 Expanding the Functional Information Search Model. Annals of Tourism Research 25:551-578.

Waschke, S.

2004 Labeling im Barrierefreien Tourismus in Deutschland - Vergleichende Analyse auf

Basis Europäischer Beispiele. Dissertation in Business Studies, University of Lüneburg, Germany.

Yau, M., B. McKercher, and T. Packer

2004 Travelling with a Disability - More than an Access Issue. Annals of Tourism

Research 31:946-960. 